\title{
Arctic sea ice and the Madden-Julian Oscillation (MJO)
}

\author{
Gina R. Henderson • Bradford S. Barrett • \\ Donald M. Lafleur
}

Received: 1 July 2013/Accepted: 26 December 2013/Published online: 5 January 2014

(C) The Author(s) 2014. This article is published with open access at Springerlink.com

\begin{abstract}
Arctic sea ice responds to atmospheric forcing in primarily a top-down manner, whereby near-surface air circulation and temperature govern motion, formation, melting, and accretion. As a result, concentrations of sea ice vary with phases of many of the major modes of atmospheric variability, including the North Atlantic Oscillation, the Arctic Oscillation, and the El NiñoSouthern Oscillation. However, until this present study, variability of sea ice by phase of the leading mode of atmospheric intraseasonal variability, the Madden-Julian Oscillation (MJO), which has been found to modify Arctic circulation and temperature, remained largely unstudied. Anomalies in daily change in sea ice concentration were isolated for all phases of the real-time multivariate MJO index during both summer (May-July) and winter (November-January) months. The three principal findings of the current study were as follows. (1) The MJO projects onto the Arctic atmosphere, as evidenced by statistically significant wavy patterns and consistent anomaly sign changes in composites of surface and mid-tropospheric atmospheric fields. (2) The MJO modulates Arctic sea ice in both summer and winter seasons, with the region of greatest variability shifting with the migration of the ice margin poleward (equatorward) during the summer (winter) period. Active regions of coherent ice concentration variability were identified in the Atlantic sector on days when the MJO was in phases 4 and 7 and the Pacific sector on days when the MJO was in phases 2 and 6, all supported by corresponding anomalies in surface wind and temperature. During July, similar variability in sea ice
\end{abstract}

G. R. Henderson $(\bowtie)$ · B. S. Barrett · D. M. Lafleur

Oceanography Department, U.S. Naval Academy,

572C Holloway Rd, Annapolis, MD 21402, USA

e-mail: ghenders@usna.edu concentration was found in the North Atlantic sector during MJO phases 2 and 6 and Siberian sector during MJO phases 1 and 5 , also supported by corresponding anomalies in surface wind. (3) The MJO modulates Arctic sea ice regionally, often resulting in dipole-shaped patterns of variability between anomaly centers. These results provide an important first look at intraseasonal variability of sea ice in the Arctic.

Keywords Madden-Julian Oscillation - Arctic sea ice . Intraseasonal variability

\section{Introduction}

Arctic sea ice is a complex component of the Earth climate system. Part of its complexity comes from its sensitivity to the atmosphere on a range of spatial and temporal scales. For example, decades of observational and modeling studies of sea ice have confirmed that its variability is primarily a top-down process (Liu et al. 2004; Deser and Teng 2008), where the atmosphere provides the primary forcing mechanisms (Hopsch et al. 2012). In response, sea ice tends to organize - via motion, formation, melting, and accretion-in accordance with large-scale patterns of atmospheric circulation (Walsh and Johnson 1979; Overland and Pease 1982; Fang and Wallace 1994; Slonosky et al. 1997; Prinsenberg et al. 1997; Overland and Wang 2010). Because of these responses to the atmosphere, concentrations of sea ice have been found to be correlated with several of the major modes of atmospheric variability, including the North Atlantic Oscillation (NAO) (Deser et al. 2000; Kwok 2000; Parkinson 2000; Partington et al. 2003), the Arctic Oscillation (AO) (Wang and Ikeda 2000; Rigor et al. 2002; Belchansky et al. 2004) (the NAO and 
AO are often referred to as part of the Northern Hemisphere annular mode; Wallace 2000), the El Niño-Southern Oscillation (ENSO) (Liu et al. 2004), and longer-period oscillations (Polyakov et al. 2003). Furthermore, the leading mode of atmospheric intraseasonal variability, the Madden-Julian Oscillation (MJO; Madden and Julian 1972), has been shown to modulate the high-latitude (Zhou and Miller 2005; Cassou 2008) and Arctic (L'Heureux and Higgins 2008; Yoo et al. 2011) atmosphere. However, connections between sea ice and the MJO remain largely unexplored. Therefore, the purpose of this paper is to examine variability of Arctic sea ice concentration by phase of the MJO.

Observational studies of sea ice organizational patterns have shown that the most important atmospheric drivers of Arctic sea ice variability are surface air temperature and surface wind (Prinsenberg et al. 1997; Deser et al. 2000; DeWeaver and Bitz 2006), with surface wind being the most important driver of summer variability (Kwok 2008; Ogi et al. 2008; Zhang et al. 2013). The dominant pattern of winter sea ice variability resembles a dipole, where ice concentration in the North Atlantic varies oppositely between the Barents and Greenland Seas and the Labrador Sea (Fang and Wallace 1994; Partington et al. 2003; Ukita et al. 2007; Parkinson and Cavalieri 2008). Another winter dipole pattern is observed in the Pacific sector between the Bering Sea and the Sea of Okhotsk, where atmospheric blocking episodes act to modulate the advance of the ice, although these fluctuations of ice concentration tend to be smaller than those in the North Atlantic sector (Ivanova et al. 2012). In summer, a prominent dipole, also seen in observational data, tends to locate between the Kara Sea and the East Siberian Sea (Fang and Wallace 1994). Throughout the year, the majority of the variability occurs along the sea ice margin, where ice meets open water (Fang and Wallace 1994; Polyakov et al. 2003; Strong 2012; Ivanova et al. 2012), driven by atmospheric forcing (Strong 2012). Significant differences between summer and winter seasons, including the direction of ice change (melting versus freezing), solar radiation received at the surface, and variability in locations of ice concentration change, result in strong seasonality in Arctic sea ice extent (Fig. 1). For this study, we were interested in modulation of both winter (November-January) and summer (May-July) sea ice by the MJO, with particular emphasis along the sea ice margins, and because of the pronounced seasonality in ice extent, summer and winter periods were treated separately.

Tropical convection, which is the primary driver of the MJO, has been found to affect atmospheric circulation in high latitudes (e.g., Ferranti et al. 1990; Higgins and Mo 1997; Matthews et al. 2004). Vecchi and Bond (2004) found that geopotential height, specific humidity, and surface air temperature in the Arctic varied by phase of the

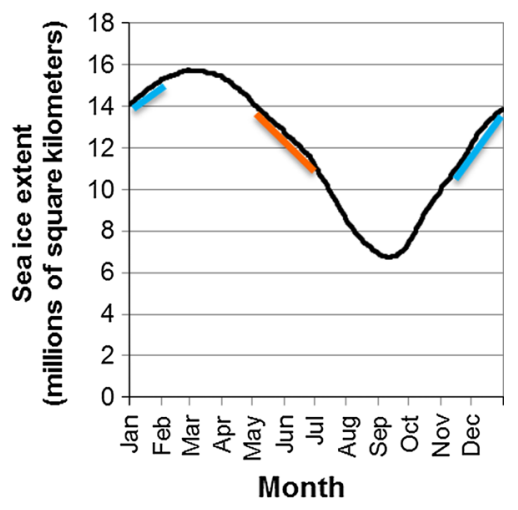

Fig. 1 Mean monthly sea ice extent, 1979-2000. Blue (orange) sections highlight transition winter (summer) seasons which were the focus of this study. Data from NSIDC's sea ice index

MJO, and the response of surface air temperature in Canada to the MJO was confirmed by Lin and Brunet (2009). Lee et al. (2011) noted that the "polar amplification" in surface temperatures was in response to poleward-propagating Rossby waves excited by MJO-related tropical convection. Yoo et al. (2012) further confirmed that the MJO-driven, poleward propagating wave train drove changes in the Arctic overturning circulation, heat flux, and downward infrared radiation, and Flatau and Kim (2013) noted that that the MJO forces the annular modes (the AO and NAO) on intraseasonal time scales. All of these Arctic parameters affected by the MJO, from atmospheric circulation to temperature to radiation, have potentially significant impacts on sea ice concentration. However, the specific effects of MJO-driven atmospheric variability on sea ice concentration are not yet known. Therefore, the purpose of this paper is to explore variability in sea ice concentration and atmospheric parameters for two periods, one in the winter freeze-up season, November-January, NDJ, and another in the summer melt season, May-July, MJJ, and then to connect the observed variability to specific phases of the MJO. Both seasonal and monthly variability will be examined on timescales of the MJO. The rest of this paper is organized as follows: datasets and methodology are described in Sect. 2, results are presented in Sect. 3, and discussion and conclusions are presented in Sect. 4.

\section{Data and methods}

The analyses in this study were based on three publicly available datasets. First, to gain an understanding of the state of the Arctic atmosphere under different phases of the MJO at both surface and mid-tropospheric levels, daily data from the National Centers for Environmental Prediction (NCEP)-Department of Energy (DOE) reanalysis 2 
(Kanamitsu et al. 2002) were examined. Variables included in the atmospheric analysis were 500-hPa geopotential height, mean sea level pressure, 2-m surface temperature, and 10-m winds, for the period 1979 to 2011. Daily composite anomalies of pressure, height, temperature and wind were created for both winter and summer months by phase of the MJO using the methodology described below.

Second, to quantify the effects of the MJO on ice, daily change in Arctic sea ice concentration $(\Delta \mathrm{SIC})$ was calculated using the NOAA/National Snow and Ice Data Center (NSIDC) Climate Data Record (CDR) of passive microwave sea ice concentration, version 2 (Meier et al. 2013). This dataset was provided on a $25 \mathrm{~km} \times 25 \mathrm{~km}$ grid for the polar region and available daily from 1987 through 2012. The years 1989-2010 were used in this study, starting in 1989 due to missing data in the beginning of the record. Ice concentrations in the CDR were produced through a combination of two mature passive microwave ice algorithms, the NASA Team (Cavalieri et al. 1984) and the Bootstrap (Comiso 1986), both using Special Sensor Microwave/Imager (SSM/I) brightness temperature data as input. Daily change in ice concentration $(\Delta \mathrm{SIC})$ was calculated at each grid box using

$\Delta S I C=d a y_{n}-d a y_{n-1}$ where $d a y_{n}$ is daily ice concentration for day $n$ and $d a y_{n-1}$ is the concentration for the previous day. Mean monthly $\Delta$ SIC for the MJJ and NDJ seasons (Fig. 2) showed areas of ice concentration loss (blues, top row) and gains (yellows, bottom row) during these respective seasons. The location of largest ice concentration loss (gain) for each season varied substantially during the summer (winter), migrating poleward (equatorward) in each subsequent month of the season.

Third, the MJO itself was defined using the daily realtime multivariate MJO (RMM) index (Wheeler and Hendon 2004). The RMM phases were used to divide the reanalysis and daily change in sea ice concentration datasets. The daily RMM index oscillates between eight phases, each corresponding to the broad location of an MJOenhanced equatorial convective signal (Wheeler and Hendon 2004). The index is created such that the MJO generally progresses eastward, from phase 1 to 8 and back to phase 1 again. Days during which the magnitude of the MJO vector was less than one standard deviation from zero were not considered, following the compositing methodology of other recent studies (e.g., Zhou et al. 2012; Virts et al. 2013; Zhang 2013; Barrett and Gensini 2013). Anomalies in daily $\triangle \mathrm{SIC}, 500-\mathrm{hPa}$ geopotential height, sea
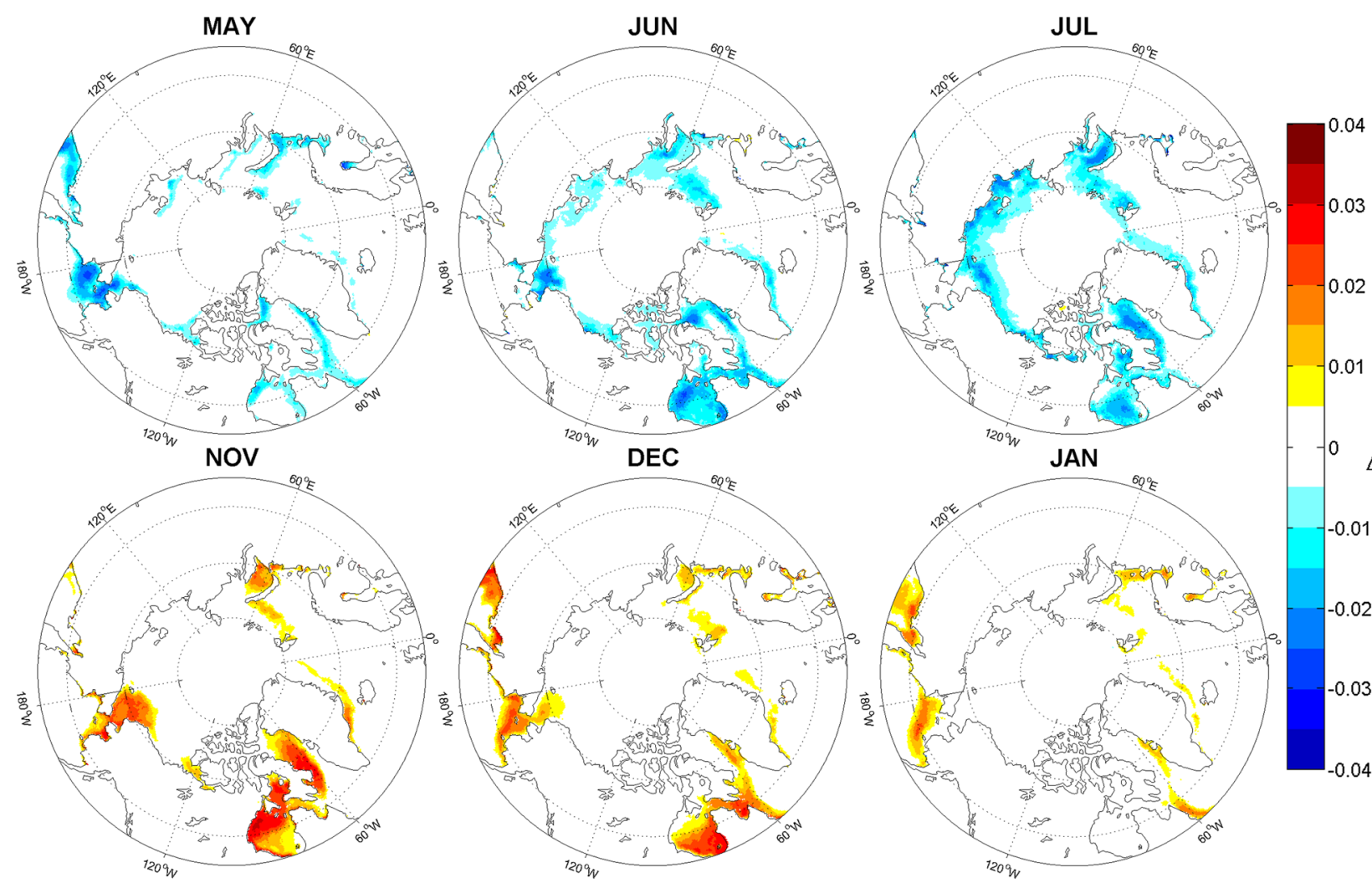

$\Delta$ SIC

Fig. 2 Mean daily change in sea ice concentration $(\Delta \mathrm{SIC}$ ) expressed as a monthly average for MJJ (top row), and NDJ (bottom row). Sea ice concentration values represent percent change. Data from 1989 to 2010 
level pressure, 2-m air temperature, and 10-m wind were then found by averaging the day $_{n}$ means for each MJO phase and subtracting them from the overall monthly mean.

To isolate relationships between the MJO and Arctic sea ice, and to remove some of the effects of the long-period decline in overall sea ice cover (e.g., Serreze et al. 2007), only daily $\triangle$ SIC beyond one standard deviation (either positive or negative) from the normal daily change for that month was used to calculate monthly anomalies; all other daily $\Delta$ SIC were not considered for the analysis. In addition to focusing on extreme values of anomalous $\triangle$ SIC, a minimum number of days threshold was imposed at each grid box, such that only those boxes in which anomalous $\Delta$ SIC values were above (or below) one standard deviation for at least 5 days, for a particular MJO phase and month, were considered. Significance testing was performed using the Student's $t$ test, and both atmospheric and sea ice anomalies were examined for significance at the $95 \%$ confidence level.

\section{Results}

\subsection{Seasonal atmosphere variability}

Composites of Arctic atmospheric circulation in both winter and summer showed statistically significant variability by phase of the MJO, with the greatest amplitude in variability occurring in winter. For November through January (Fig. 3), the pattern of $500-\mathrm{hPa}$ height anomalies was found to be wavy and to exhibit a variety of wavenumbers. For example, in Phase 4, negative anomalies over northeast Russia and Alaska changed signs to positive anomalies over northern North America, and then changed sign again to negative over the north Atlantic and northern Europe. The anomaly centers also tended to change signs with phase of the MJO, something which is a defining characteristic of MJO-related variability (Zhang 2013). For example, in MJO phase 1, negative height anomalies were found over northern Russia, Alaska, and the north Atlantic, and positive height anomalies were found over northern Europe and North America. By phase 5, positive height anomalies were centered over much of Russia, while negative height anomalies were located over much of Western Europe. In winter (November-January), the height anomalies on days with the MJO in phase 2 resembled an anomalously positive AO polarity, and on days when the MJO was in phase 6 and 7, the height anomalies resembled negative AO polarity. This agreed well with the findings of Flatau and Kim (2013), who noted that convection in the Indian Ocean (MJO phase 2) was associated with positive $\mathrm{AO}$ polarity.

In summer (May-July), similar wavy patterns in the 500-hPa height anomalies were found (Fig. 4), although the magnitude of the anomalies was less than in winter. Similar to winter, the signs of anomaly centers tended to change with phase of the MJO. For example, in Phase 2, positive anomalies were located over the Bering Strait and Sea and the North Atlantic, and negative anomalies over northern Europe and North America, and by Phase 6, the signs of these anomalies had shifted, with positive height anomalies over northern Europe and North America and negative height anomalies over the Bering Strait. In addition to the findings described above, the influence of MJO in the Arctic in boreal summer (phases 1 and 8) indicated tendencies of a positive AO signal, while phases 5 and 6 pointed to a negative AO oscillation. This boreal summer MJO-AO relationship has not received much attention in published literature to date. Both the winter and summer height anomaly patterns showed that the Arctic atmosphere varies significantly with phase of the MJO. Establishing seasonal variability of the Arctic atmosphere by MJO phase was a necessary first step in our postulation of a topdown theory of how the MJO modulates the Arctic atmosphere, and subsequently, Arctic sea ice.

\subsection{Monthly atmosphere and ice variability}

The MJO was found to project onto the Arctic atmosphere on seasonal time scales (Figs. 3, 4). However, when considering associations between atmospheric tendencies and sea ice variability, sub-seasonal temporal scale was necessary because monthly $\Delta$ SIC anomalies migrated poleward during summer (MJJ) and equatorward during winter (NDJ) seasons, respectively (Fig. 2). Locations of anomalous $\triangle$ SIC by phase of MJO also demonstrated regional variability across the Arctic domain. Two leading regions of sea ice variability identified previously in the literature were the Barents and Greenland Seas and the Labrador Sea in the Atlantic sector, and the Bering Sea and the Sea of Okhotsk in the Pacific sector. To better identify patterns in anomalous $\triangle$ SIC by phase of MJO, we used a sector-based approach using regions defined in the widely used Multisensored Analyzed Sea Ice Extent (MASIE) (National Ice Center and NSIDC 2010) product, identified in Fig. 5. Here, we highlight results from 2 months, January and July, which were typical of patterns seen in other months in both winter and summer.

In January, sea ice variability by phase of the MJO showed several important characteristics. First, $\Delta$ SIC variability tended to concentrate the most in two sectors: the North Atlantic, where the most variability occurred between MJO phases 4 and 7 and extended from either side of Greenland to the Barents Sea (column 4 in Fig. 6), and the Pacific, where the most variability occurred between MJO phases 2 and 6 and extended from the Sea of Okhotsk to the Bering Sea (column 4 in Fig. 7). Second, the largest 
Fig. 3 Daily 500-hPa height anomalies (in $\mathrm{m}$ ), for each of the 8 MJO phases. Anomalous values are expressed as a seasonal mean, NovemberJanuary. Reanalysis data from 1980 to 2011
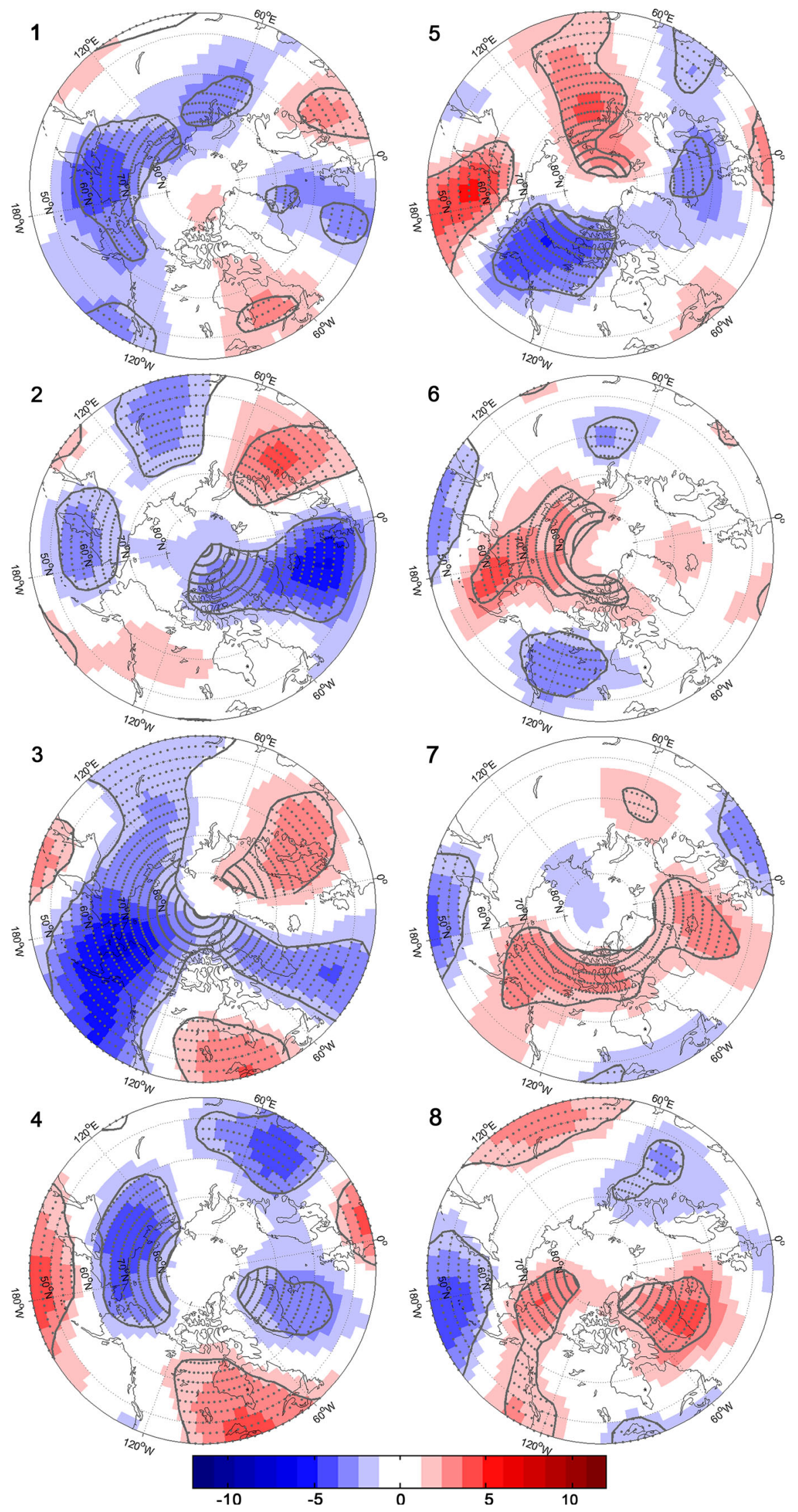
Fig. 4 As in Fig. 3, but for May-July
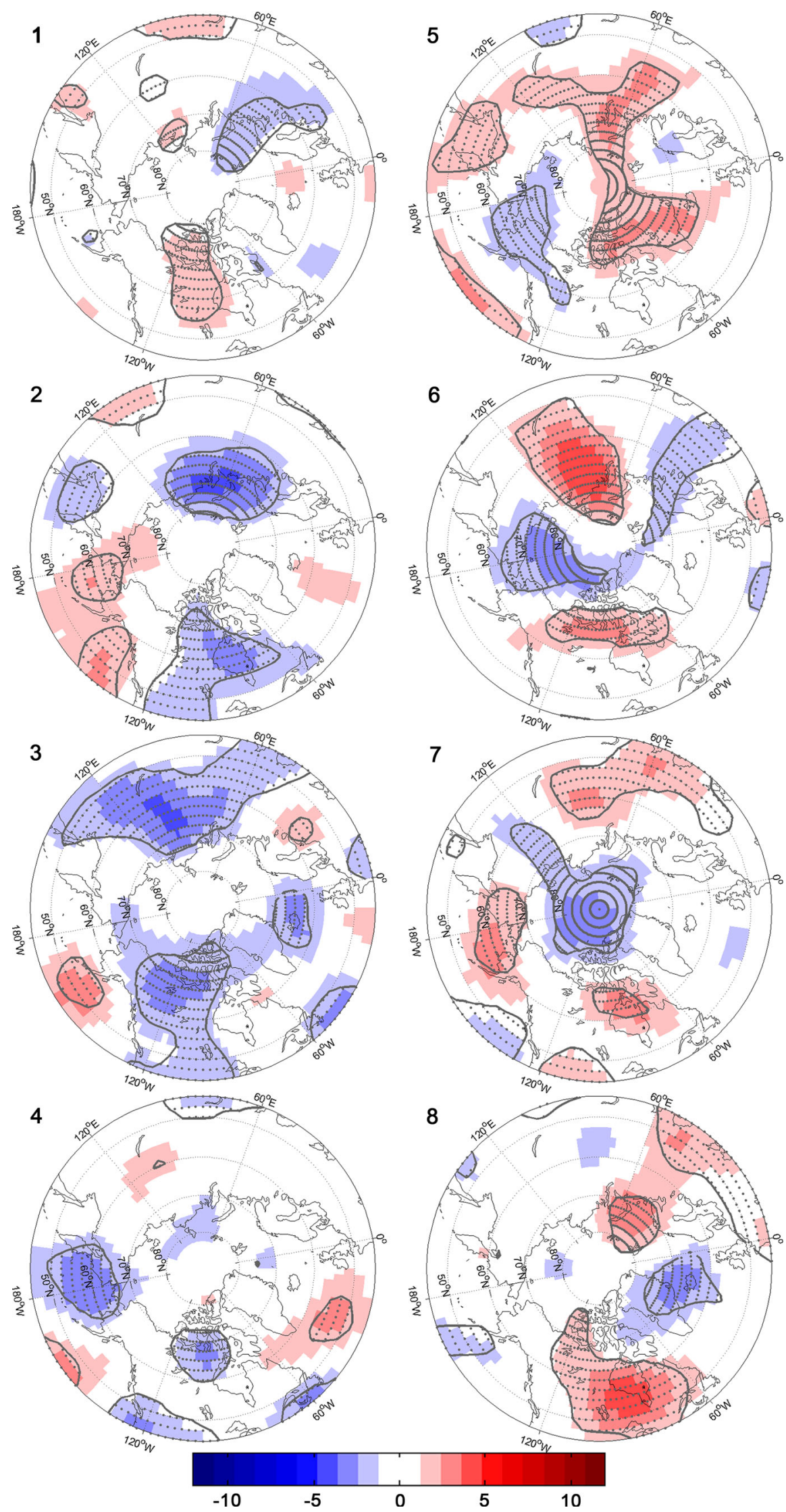


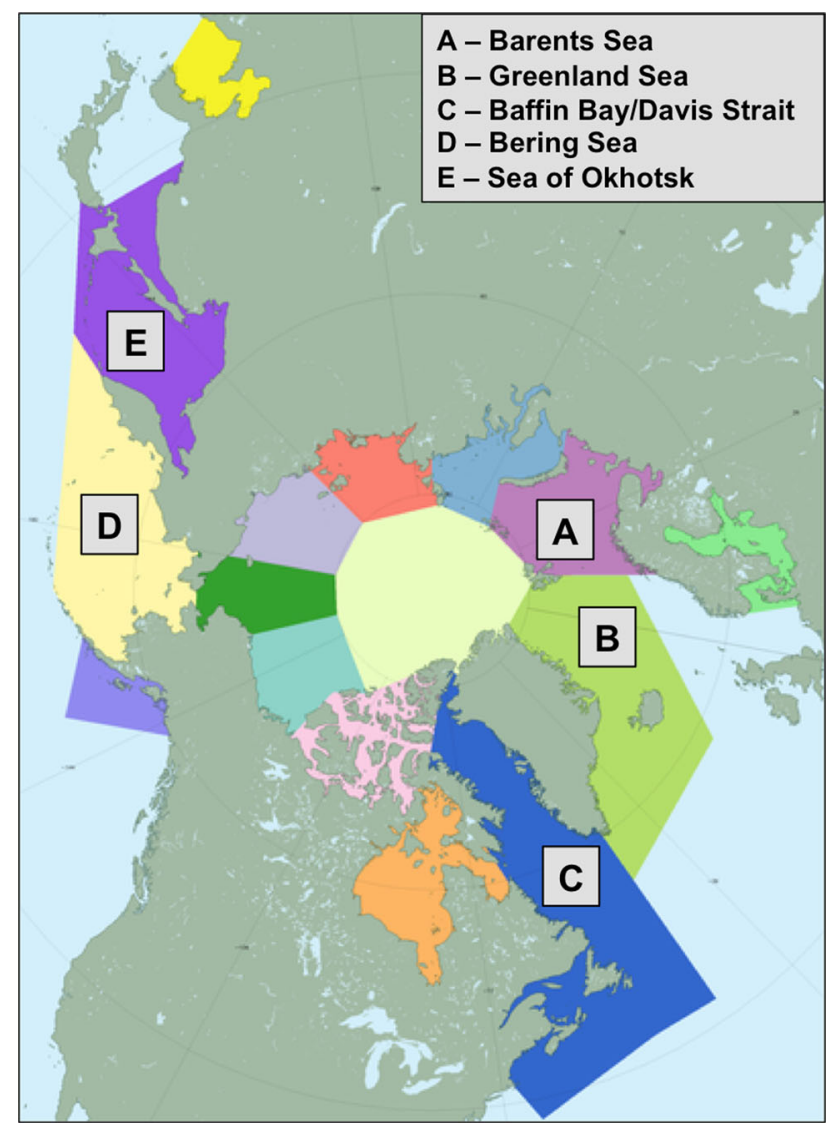

Fig. 5 Multisensored Analyzed Sea Ice Extent (MASIE) defined Arctic regions (National Ice Center and NSIDC 2010)

range in variability of January sea ice concentration in the Atlantic ( -0.1 to 0.1$)$ occurred during MJO phases 4 and 7 (Fig. 6), and the largest range in variability of January sea ice concentration in the Pacific $(-0.1$ to 0.1$)$ occurred during Phases 2 and 6 (Fig. 7). Anomalies of daily change in sea ice concentration were less variable (more neutral) during other MJO phases, and thus are not shown. Third, $\triangle$ SIC anomalies in all four phases examined here $(2,4,6$, and 7) were supported by corresponding atmospheric circulation and temperature anomalies. For example, on days when the MJO was in phase 4 (Fig. 6, top row), statistically significant (at the $95 \%$ level) anomalous daily changes in sea ice concentrations resembled the dipole structure reported by Fang and Wallace (1994), Partington et al. (2003), Ukita et al. (2007), and Parkinson and Cavalieri (2008). Negative anomalies were found along the east coast of Greenland and positive anomalies were found in the Barents Sea; the sign of these anomalies flipped on days when the MJO was in phase 7 (Fig. 6, bottom row). On days when the MJO was in phase 4, mean sea level pressure was anomalously low over the Barents Sea, which caused anomalously northerly surface winds in the Greenland Sea and anomalously southerly surface winds in the Barents Sea. When the MJO was in phase 7, mean sea level pressure was anomalously high over the Barents Sea, leading to opposite wind anomalies than for days when the MJO was in phase 4 (Fig. 6). Northerly surface winds over the Greenland Sea (like those during phase 4) would push sea ice away from Greenland, decreasing the sea ice concentration along its eastern coast, while southerly surface winds (like those during phase 7) would push ice back north toward Greenland and increase the sea ice concentration. For the other half of the dipole, in the eastern Barents Sea, weak northerly surface winds and belownormal surface temperatures during phase 4 agreed with anomalous positive change in sea ice concentration, while during phase 7 , anomalous southerly winds and abovenormal surface temperatures agreed with the observed anomalous negative change in sea ice concentration.

Similar agreement between the atmosphere and anomalous daily change in sea ice concentration was found in the Pacific sector (Fig. 7). For example, on days when the MJO was in phase 2 (Fig. 7, top row), negative surface pressure anomalies were located over the Bering Strait and Chukchi Sea, leading to northerly surface wind anomalies over the Bering Sea and below-normal surface temperatures (as much as $6 \mathrm{~K}$ below January normal) in the Sea of Okhotsk, concurrent with an increase in sea ice concentration in both locations. On days when the MJO was in phase 6 (Fig. 7, bottom row), sea level pressure anomalies in the Bering Strait and Chukchi Sea were positive, leading to strong southerly surface wind anomalies (up to $5 \mathrm{~m} \mathrm{~s}^{-1}$ ) and positive surface temperature anomalies over the Sea of Okhotsk, concurrent with a decrease in sea ice concentration. For the Pacific sector, surface temperature anomalies seemed to be most strongly related to anomalous change in sea ice concentration. However, in the Atlantic sector surface wind anomalies seemed to be most strongly related to anomalous change in sea ice concentration, in good agreement with Prinsenberg et al. (1997), Deser et al. (2000), and DeWeaver and Bitz (2006), who all noted important effects of surface wind anomalies on Atlantic sea ice concentration in winter.

In July, unlike January, $\Delta$ SIC anomalies tended to concentrate in Atlantic and Siberian sectors. In the Atlantic sector, on days when the MJO was in phase 2, positive ice concentration change anomalies were found from the northern Barents Sea westward to the east coast of Greenland (Fig. 8, top row). These anomalies largely reversed for days when the MJO was in phase 6 (Fig. 8, bottom row). Anomalies of atmospheric circulation were found supporting these ice anomalies. In phase 2, negative sea level pressure anomalies were centered over the Kara, Barents, and Labrador seas, with largely northerly wind anomalies east of Greenland and near-calm winds west of Greenland. In phase 6, sea level pressures were above 

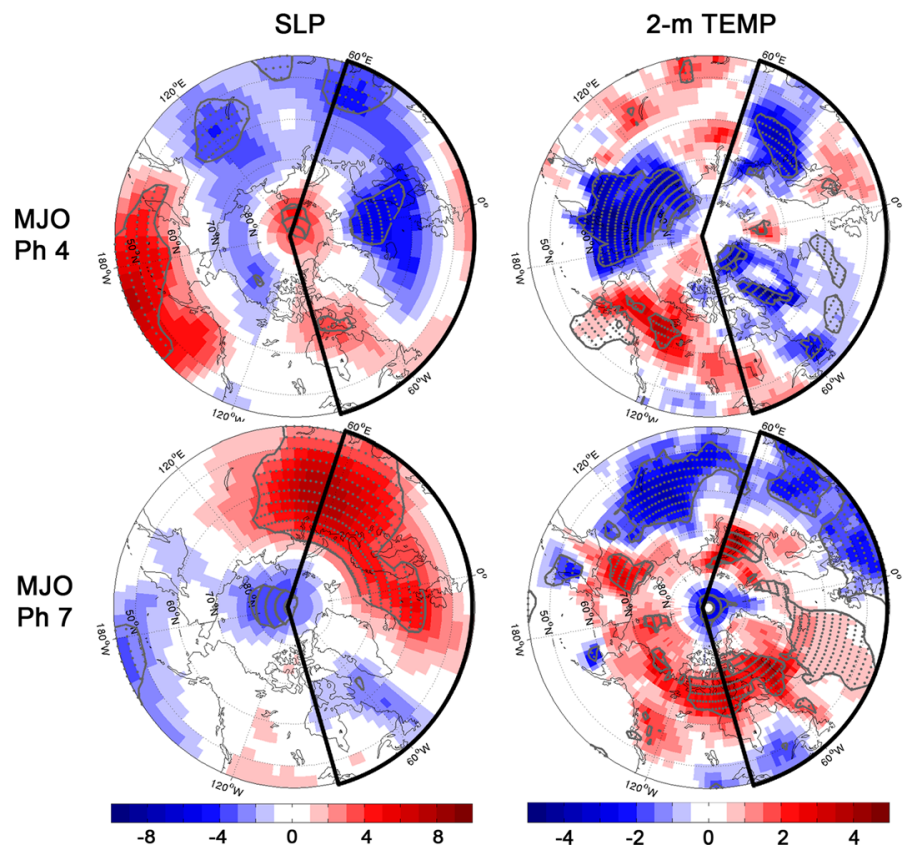

Fig. 6 Daily composites of anomalous sea level pressure (SLP, in $\mathrm{hPa}$ ), 2-m temperature (TEMP, in $\left.{ }^{\circ} \mathrm{C}\right), 10-\mathrm{m}$ winds $(10 \mathrm{~m} \mathrm{WND}$, in $\mathrm{m} \mathrm{s}^{-1}$ ), and change in SIC ( $\Delta \mathrm{SIC}$, in $\%$ change) for active MJO phases 4 and 7 for January. All variables are expressed as anomalies
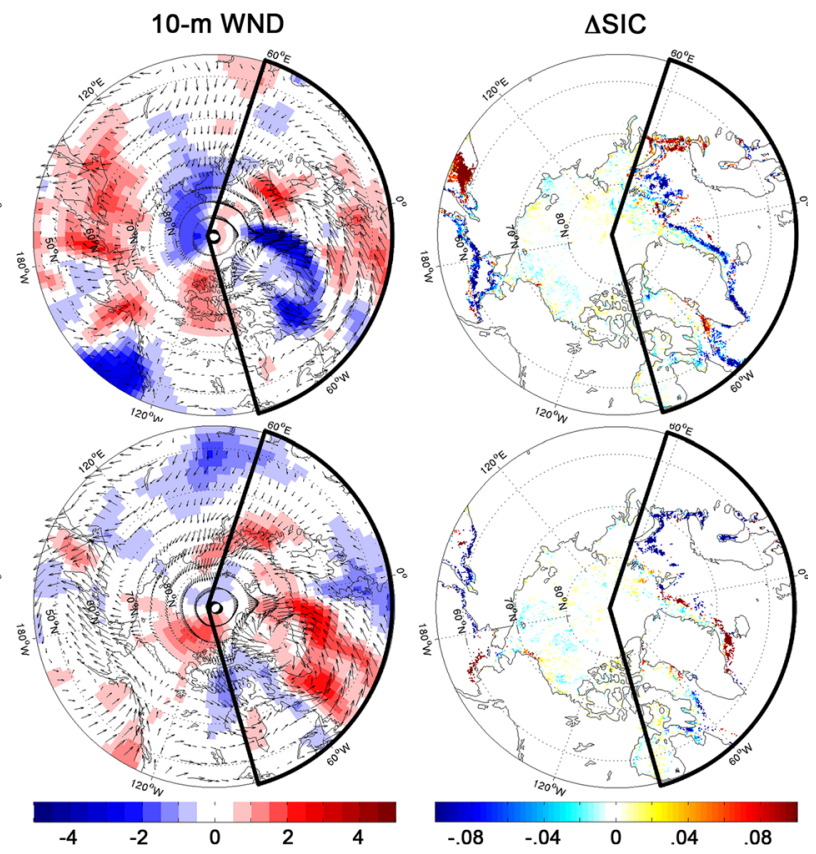

from the monthly mean, except $10-\mathrm{m}$ winds, where the arrows represent mean daily velocity and shading indicates magnitude of anomalous $v$-wind component. Reanalysis data are from 1980 to 2011 and ice concentrations are from 1989 to 2010
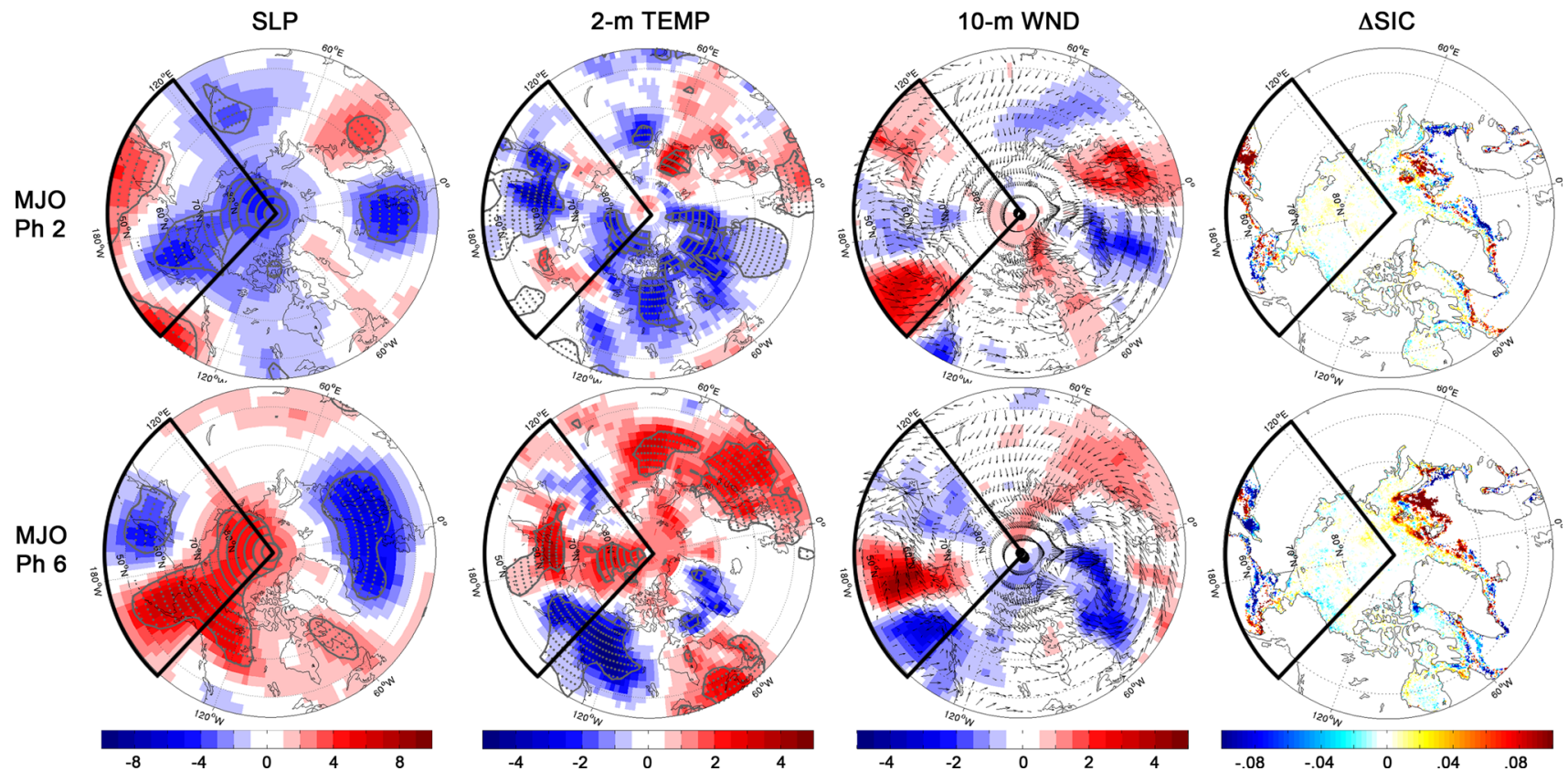

Fig. 7 As in Fig. 6, but for phases 2 and 6 for January

normal over the Kara Sea and below-normal over Baffin Bay, with largely southerly wind anomalies over the Greenland Sea and negative anomalies over the Davis Strait. Northerly (southerly) wind anomalies would tend to push ice away from (toward) the summer-season ice source, the central Arctic Ocean, and toward (away from) land, supporting the near-shore ice anomalies seen in phases 2 and 6 (Fig. 8). Near-normal temperature anomalies were found over the North Atlantic sector in both phases, suggesting that for the North Atlantic, July 
variability in sea ice was driven primarily by variability in surface wind, in good agreement with Kwok (2008), Ogi et al. (2008), and Zhang et al. (2013).

In the Siberian sector in July, on days when the MJO was in phase 1 (Fig. 9, top row), mostly negative anomalies in daily $\triangle$ SIC were located over the Kara and Laptev seas. On days when the MJO was in phase 5, ice concentration anomalies were reversed, with mostly positive change in sea ice concentration over the Kara and Laptev seas (Fig. 9, bottom row). Similar to the North Atlantic sector (and unlike January), atmospheric anomalies by MJO phase were mostly neutral in the Siberian sector, with a few small but key anomalies in sea level pressure driving changes in surface wind that explain observed changes in
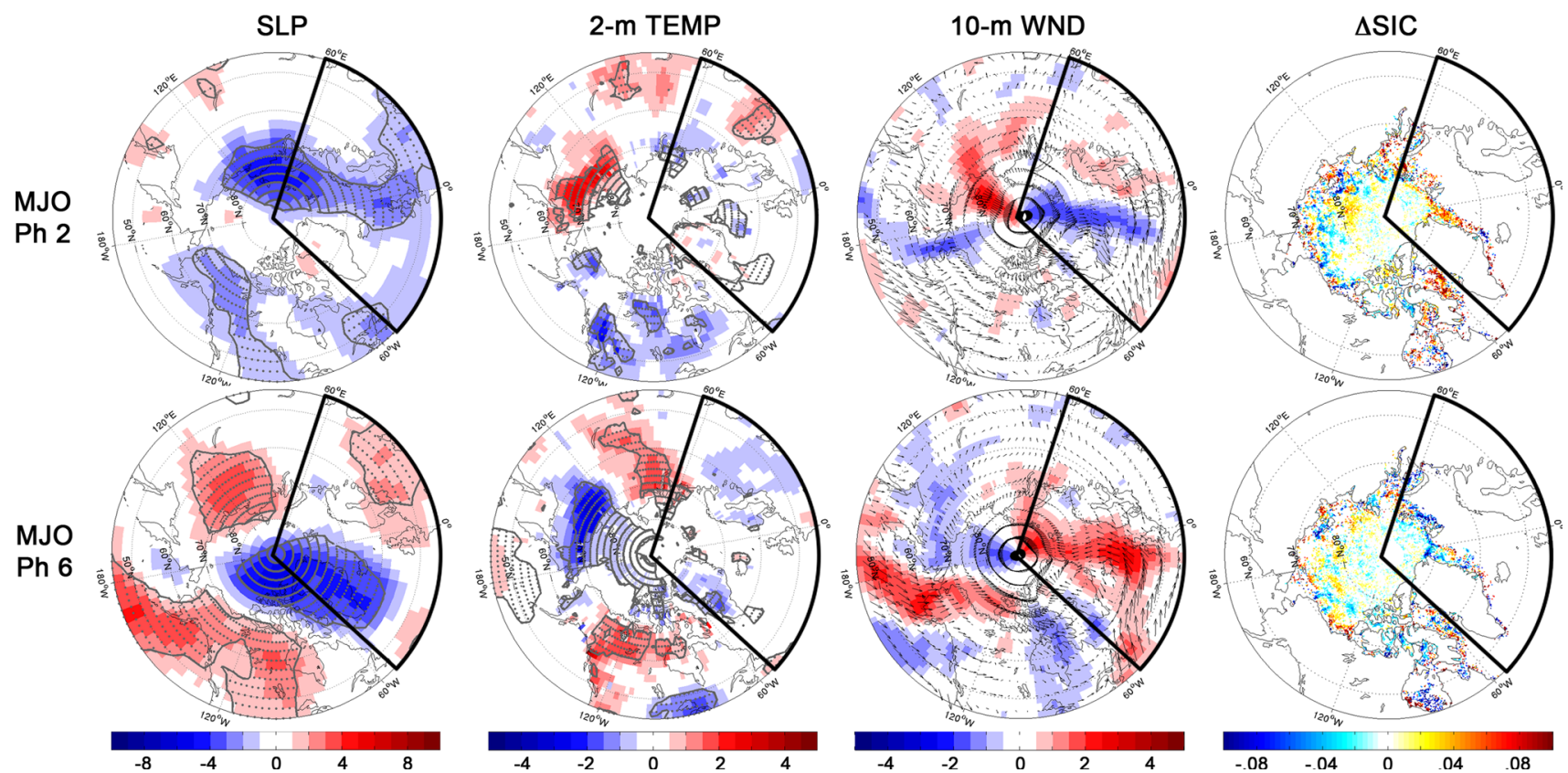

Fig. 8 As in Fig. 6, but for phases 2 and 6 for July
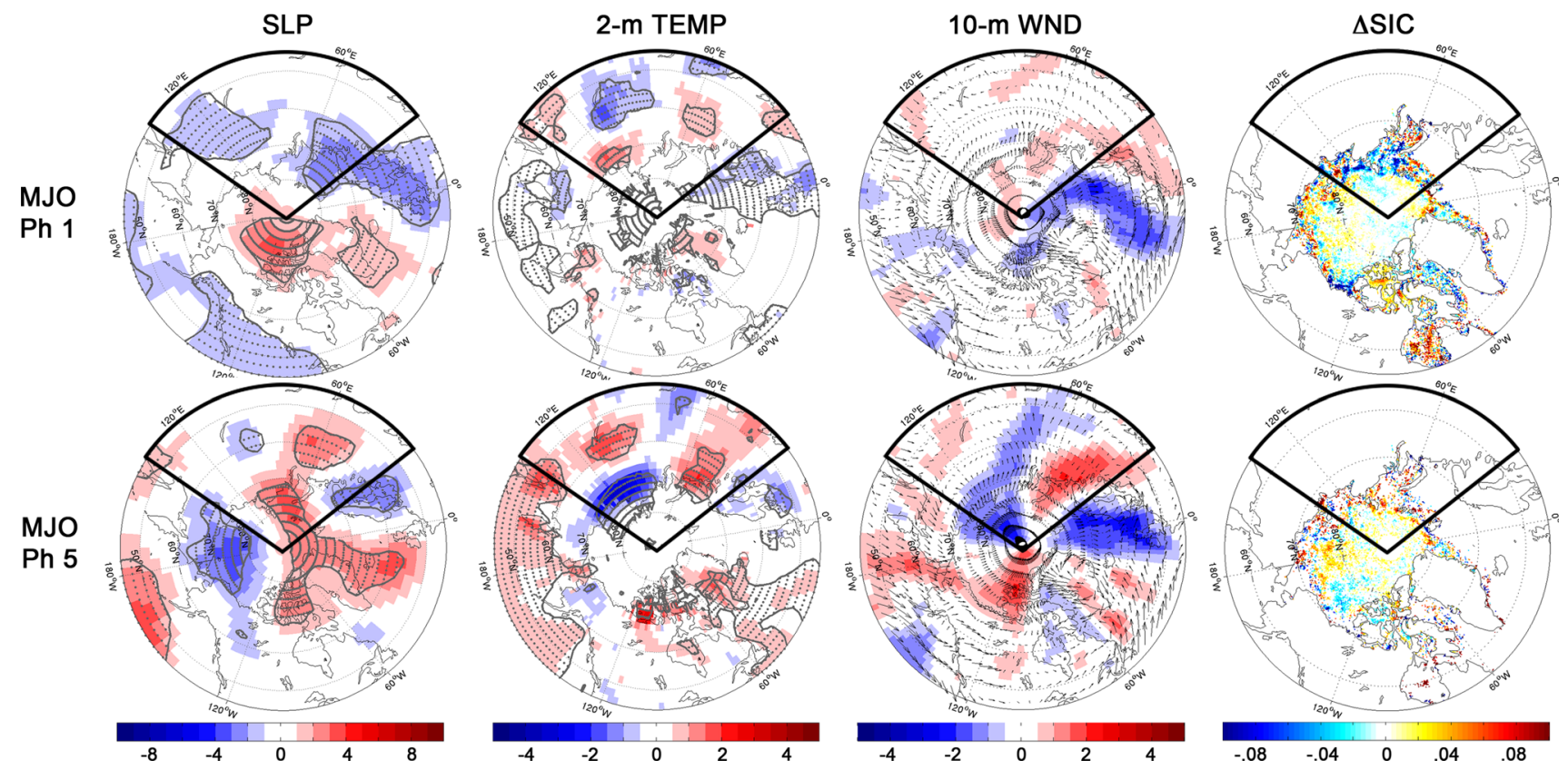

Fig. 9 As in Fig. 6, but for phases 1 and 5 for July 
ice. For example, during phase 1, sea level pressures were negative over the Kara Sea and positive over the northern East Siberian Sea, yielding weakly positive surface wind anomalies that would act to transport ice poleward, supporting observed negative changes in ice concentration over the Siberian sector. During phase 5, the pressure dipole pattern reversed, with positive sea level pressures over the Kara Sea and negative pressures over the East Siberian Sea, yielding anomalously northerly surface winds that would act to push ice out of the central Arctic and into the Siberian sector, supporting observed positive chances in ice concentration.

\section{Discussion and conclusions}

The goal of this paper was to explore variability in the Arctic atmosphere and sea ice concentration, and to connect such variability with phases of the MJO. Recent studies have heralded significant association between phase of the MJO and high-latitude terrestrial surface air temperature, atmospheric circulation, geopotential height, specific humidity (Ferranti et al. 1990; Higgins and Mo 1997; Matthews et al. 2004; Vecchi and Bond 2004; Zhou and Miller 2005; Cassou 2008; Lin and Brunet 2009). In addition, modulation of the Arctic atmosphere specifically by phase of MJO has also been documented (L'Heureux and Higgins 2008; Yoo et al. 2011). However, none of the previous works cited have considered associations between sea ice concentration and phase of MJO.

The three principal findings of the current study are as follows. (1) The MJO projects onto the Arctic atmosphere in both winter (NDJ) and summer (MJJ) seasons. This projection was evident from the distinct wavy pattern in 500-hPa geopotential height anomalies (Figs. 3, 4), and it confirms the earlier work of Vecchi and Bond (2004) and Yoo et al. (2012). Both location and sign of height anomalies displayed a tendency to flip every 3-5 phases of the MJO. This MJO-mid tropospheric connection also proved robust, being visible in 3-month seasonal plots with statistically significant anomalies at the $95 \%$ level, in both winter and summer seasons. Furthermore, in NDJ, height anomalies in phase 2 resembled positive AO polarity while height anomalies in phases 6 and 7 resembled negative AO polarity, in good agreement with Flatau and Kim (2013). (2) Variability in sea ice concentration by phase of MJO was found in both summer and winter seasons, and this variability was supported by corresponding anomalies in the state of the atmosphere. The magnitude of variability tended to shift largely with the migration of the ice margin poleward (equatorward) during the summer (winter) period. By computing anomalous $\triangle$ SIC per month, and binning by phase of $\mathrm{MJO}$, active regions of coherent ice concentration variability were identified in both Atlantic and Pacific sectors for specific phases during January (Figs. 6, 9) and for North Atlantic and Siberian sectors during July. The signs of anomalies (positive or negative) for specific MJO phases changed with season. In January, areas of positive (negative) $\Delta \mathrm{SIC}$ in the Atlantic sector were collocated with southerly (northerly) wind anomalies, with southerly (northerly) winds pushing ice toward (away from) land resulting in anomalously positive (negative) change in concentration. In the Pacific sector in January, areas of positive (negative) $\Delta$ SIC were collocated with negative (positive) surface temperature anomalies, with colder (warmer) surface temperatures promoting local increases (decreases) in ice concentration. In July, areas of positive (negative) $\Delta \mathrm{SIC}$ in both the North Atlantic and Siberian sectors were collocated with northerly (southerly) surface wind anomalies, as unlike in January, northerly (southerly) winds acted to push ice away from (toward) the primary ice source region (the central Arctic), leading to positive (negative) changes in ice concentration. Sea level pressure anomalies were found to support the observed variability in surface wind. (3) The MJO modulates Arctic sea ice regionally, often resulting in dipole-shaped variability between anomaly centers. The most commonly observed dipoles occurred between the Barents and Greenland seas in January, in agreement with Ivanova et al. (2012). All four sectors (Atlantic and Pacific in winter, and North Atlantic and Siberian in summer) demonstrated instances of ice anomalies that changed sign approximately every 3-4 phases of the MJO, as evidenced from the January and July examples presented in this study. These changes in sign of anomalous $\Delta$ SIC corresponded with similar changes in surface pressure, surface wind, and midtropospheric geopotential height, and suggest a physical robustness to the MJO-sea ice relationship.

It is important to note that accelerating decline in extent of multi-year sea ice over the last several decades has cast some doubt on earlier findings of ice-climate relationships, particularly between sea ice and phase of the NAO. For example, during winter, cyclonic surface air flow promotes ice export through the Fram Strait (Jung and Hilmer 2001), particularly export of multi-year ice (Deser and Teng 2008), leaving the newer, thinner pack more vulnerable to forcings including enhanced downward longwave radiation (Francis and Hunter 2006) and circulation (Comiso 2006; Maslanik et al. 2007; Francis and Hunter 2007). This process has accelerated with the changing character of sea ice, and perhaps also expanded the ice margins that are susceptible to changes in atmospheric circulation and temperature that vary by phase of the MJO. To mitigate potential effects of the long-term decline in overall sea ice extent, in this study, we imposed several restrictions on the sea ice concentration data. First, we only examined daily 
$\Delta$ SIC that was more than one standard deviation above (or below) normal. Second, we excluded grid points from the analysis with fewer than 6 days of non-zero daily change in sea ice concentration (thus ensuring focus on the ice margins). Third, only sea ice anomalies that were statistically significant at the $95 \%$ confidence interval were plotted in Figs. 6, 7, 8, 9 (column four of each figure). These three restrictions served to amplify the MJO-ice signal by removing regions of insignificant variability, particularly toward the center of the Arctic.

The results presented in this paper show statistically significant variability in Arctic sea ice by phase of the MJO that is well supported by corresponding tendencies in surface wind and surface air temperature. While the specific phase relationships may well change, the MJO will continue to project onto the Arctic and modify sea ice at the ice margins, and may become even more prominent due, in particular, to the decline in thicker multi-year ice. With the tendency for thinner and more vulnerable first-year ice to occupy a greater fraction of the Arctic, the MJO-sea ice relationship shown here may become even more prominent under our changing Arctic climate. A follow-on study is underway to explore these future relationships.

Acknowledgments The authors thank American Society for Engineering Education (ASEE) Science and Engineering Apprenticeship Program (SEAP) interns Anna Haschert and Cassandra Marino for assistance in manuscript preparation. Funding for this research was provided by the National Science Foundation under Grant ARC1203843.

Open Access This article is distributed under the terms of the Creative Commons Attribution License which permits any use, distribution, and reproduction in any medium, provided the original author(s) and the source are credited.

\section{References}

Barrett BS, Gensini V (2013) Modulation of daily U.S. April-May tornado frequency by the Madden-Julian Oscillation. Geophys Res Lett 40(11):2790-2795. doi:10.1002/grl.50522

Belchansky GI, Douglas DC, Platonov NG (2004) Duration of the Arctic sea ice melt season: regional and interannual variability, 1979-2001. J Clim 17(1):67-80. doi:10.1175/1520-0442(2004) $017<0067$ :DOTASI $>2.0 . \mathrm{CO} ; 2$

Cassou C (2008) Intraseasonal interaction between the MaddenJulian Oscillation and the North Atlantic Oscillation. Nature 455(7212):523-527. doi:10.1038/nature07286

Cavalieri DJ, Gloersen P, Campbell WJ (1984) Determination of sea ice parameters with the NIMBUS-7 SMMR. J Geophys Res 89(D4):5355-5369

Comiso JC (1986) Characteristics of Arctic winter sea ice from satellite multispectral microwave observations. J Geophys Res 91(C1):975-994

Comiso JC (2006) Abrupt decline in the Arctic winter sea ice cover. Geophys Res Lett 33(18):L18504. doi:10.1029/2006GL027341

Deser C, Teng H (2008) Evolution of Arctic sea ice concentration trends and the role of atmospheric circulation forcing,
1979-2007. Geophys Res Lett 35(2):L02504. doi:10.1029/ 2007GL032023

Deser C, Walsh JE, Timlin MS (2000) Arctic sea ice variability in the context of recent atmospheric circulation trends. J Clim 13(3):617-633. doi:10.1175/1520-0442(2000)013<0617:ASI VIT $>2.0 . \mathrm{CO} ; 2$

DeWeaver E, Bitz CM (2006) Atmospheric circulation and its effect on Arctic sea ice in CCSM3 Simulations at medium and high resolution. J Clim 19(11):2415-2436

Fang Z, Wallace JM (1994) Arctic sea ice variability on a timescale of weeks: its relation to atmospheric forcing. J Clim 7(12): 1897-1913

Ferranti L, Palmer TN, Molteni F, Klinker E (1990) Tropicalextratropical interaction associated with the 30-60-day oscillation and its impact on medium and extended range prediction. J Atmos Sci 47(18):2177-2199

Flatau M, Kim YJ (2013) Interaction between the MJO and Polar Circulations. J Clim 26(11):3562-3574. doi:10.1175/JCLI-D-1100508.1

Francis JA, Hunter E (2006) New insight into the disappearing Arctic sea ice. EOS Trans AGU 87(46):509-511

Francis JA, Hunter E (2007) Drivers of declining sea ice in the Arctic winter: a tale of two seas. Geophys Res Lett 34(17):L17503. doi:10.1029/2007GL030995

Higgins RW, Mo KC (1997) Persistent North Pacific circulation anomalies and the tropical intraseasonal oscillation. J Clim 10(2):223-244

Hopsch S, Cohen J, Dethloff K (2012) Analysis of a link between fall Arctic sea ice concentration and atmospheric patterns in the following winter. Tellus 64:18624

Ivanova DP, McClean JL, Hunke EC (2012) Interaction of ocean temperature advection, surface heat fluxes, and sea ice in the marginal ice zone during the North Atlantic Oscillation in the 1990s: a modeling study. J Geophys Res 117(C2):C02031. doi:10.1029/2011JC007532

Jung T, Hilmer M (2001) The link between the North Atlantic Oscillation and Arctic sea ice export through Fram Strait. J Clim 14(19):3932-3943

Kanamitsu M, Ebisuzaki W, Woollen J, Yang S-K, Hnilo JJ, Fiorino M, Potter GL (2002) NCEP-DOE AMIP-II Reanalysis (R-2). Bull Amer Meteor Soc 83(11):1631-1643. doi:10.1175/BAMS83-11-1631

Kwok R (2000) Recent changes in Arctic Ocean sea ice motion associated with the North Atlantic Oscillation. Geophys Res Lett 27(6):775-778. doi:10.1029/1999GL002382

Kwok R (2008) Outflow of Arctic sea ice into the Greenland and Barents Seas: 1979-2007. J Clim 22(9):2438-2457. doi:10.1175/ 2008JCLI2819.1

L'Heureux ML, Higgins R (2008) Boreal winter links between the Madden-Julian Oscillation and the Arctic Oscillation. J Clim 21(12):3040-3050

Lee S, Gong T, Johnson N, Feldstein S, Pollard D (2011) On the possible link between tropical convection and the Northern Hemisphere Arctic surface air temperature change between 1958 and 2001. J Clim 24(16):4350-4367

Lin H, Brunet G (2009) The influence of the Madden-Julian oscillation on Canadian wintertime surface air temperature. Mon Weather Rev 137(7):2250-2262

Liu JP, Curry JA, Hu YY (2004) Recent Arctic sea ice variability: connections to the Arctic Oscillation and the ENSO. Geophys Res Lett 31(9):L09211. doi:10.1029/2004GL019858

Madden RA, Julian PR (1972) Description of global-scale circulation cells in the tropics with a $40-50$ day period. J Atmos Sci 29(6):1109-1123

Maslanik J, Drobot S, Fowler C, Emery W, Barry R (2007) On the Arctic climate paradox and the continuing role of atmospheric 
circulation in affecting sea ice conditions. Geophys Res Lett 34(3):L03711. doi:10.1029/2006GL028269

Matthews AJ, Hoskins BJ, Masutani M (2004) The global response to tropical heating in the Madden-Julian oscillation during the northern winter. Quart J Roy Meteorol Soc 130(601): 1991-2011

Meier W, Fetterer F, Savoie M, Mallory S, Duerr R, Stroeve J (2013) NOAA/NSIDC climate data record of passive microwave sea ice concentration. Boulder, Colorado USA: National Snow and Ice Data Center. doi:10.7265/N55M63M1

National Ice Center (NIC) and NSIDC (2010) Multisensor analyzed sea ice extent-northern hemisphere. Developed by Fetterer F, Savoie M, Helfrich S, Clemente-Colón P. Boulder, Colorado USA: National Snow and Ice Data Center. doi:10.7265/ N5GT5K3K

Ogi M, Rigor IG, McPhee MG, Wallace JM (2008) Summer retreat of Arctic sea ice: role of summer winds. Geophys Res Lett 35(24):L24701. doi:10.1029/2008GL035672

Overland JE, Pease CH (1982) Cyclone climatology of the Bering Sea and its relation to ice extent. Mon Wea Rev 110(1):5-13

Overland JE, Wang M (2010) Large-scale atmospheric circulation changes are associated with the recent loss of Arctic sea ice. Tellus 62A(1):1-9

Parkinson CL (2000) Recent trend reversals in Arctic sea ice extents: possible connections to the North Atlantic Oscillation. Polar Geogr 24(1):1-12

Parkinson CL, Cavalieri DJ (2008) Arctic sea ice variability and trends, 1979-2006. J Geophys Res 113(C7):C07003. doi:10. 1029/2007JC004558

Partington K, Flynn T, Lamb D, Bertoia C, Dedrick K (2003) Late twentieth century Northern Hemisphere sea-ice record from U.S. National Ice Center ice charts. J Geophys Res 108(C11):3343. doi:10.1029/2002JC001623

Polyakov IV, Alekseev GV, Bekryaev RV, Bhatt US, Colony R, Johnson MA, Karklin VP, Walsh D, Yulin AV (2003) Long-term ice variability in Arctic marginal seas. J Clim 16(12):2078-2085

Prinsenberg SJ, Peterson IK, Narayanan S, Umoh JU (1997) Interaction between atmosphere, ice cover, and ocean off Labrador and Newfoundland from 1962-1992. Can J Fish Aquat Sci 54(39):30-39

Rigor IG, Wallace JM, Colony RL (2002) Response of sea ice to the Arctic Oscillation. J Clim 15(18):2648-2663. doi:10.1175/15200442015<2648:ROSITT $>2$.0.CO;2

Serreze MC, Holland MM, Stroeve J (2007) Perspectives on the Arctic's shrinking sea-ice cover. Science 315(5818):1533-1536. doi:10.1126/science.1139426
Slonosky VC, Mysak LA, Derome J (1997) Linking Arctic sea ice and atmospheric circulation anomalies on interannual and decadal time scales. Atmos-Ocean 35(3):333-366

Strong C (2012) Atmospheric influence on Arctic marginal ice zone position and width in the Atlantic sector, February-April 1979-2010. Clim Dyn 39(12):3091-3102

Ukita J, Honda M, Nakamura H, Tachibana Y, Cavalieri DJ, Parkinson CL, Koide H, Yamamoto K (2007) Northern Hemisphere sea ice variability: lag structure and its implications. Tellus A 59(2):261-272

Vecchi GA, Bond NA (2004) The Madden-Julian Oscillation (MJO) and northern high latitude wintertime surface air temperatures. Geophys Res Lett 31(4):L04104. doi:10.1029/2003GL018645

Virts KS, Wallace JM, Hutchins ML, Holzworth RH (2013) Diurnal lightning variability over the Maritime Continent: impact of lowlevel winds, cloudiness, and the MJO. J Atmos Sci 70(10):3128-3146. doi:10.1175/JAS-D-13-021.1

Wallace JM (2000) North Atlantic Oscillation/annular mode: two paradigms-one phenomenon. Quart J Roy Meteorol Soc 126(564):791-805

Walsh JE, Johnson CM (1979) An analysis of Arctic sea ice fluctuations. J Phys Oceanogr 9(3):580-591

Wang J, Ikeda M (2000) Arctic Oscillation and Arctic Sea-Ice Oscillation. Geophys Res Lett 27(9):1287-1290

Wheeler MC, Hendon HH (2004) An all-season real-time multivariate MJO index: development of an index for monitoring and prediction. Mon Weather Rev 132(8):1917-1932

Yoo C, Feldstein SB, Lee S (2011) The impact of the Madden-Julian Oscillation trend on the Arctic amplification of surface air temperature during the 1979-2008 boreal winter. Geophys Res Lett 38(24):L24804. doi:10.1029/2011GL049881

Yoo C, Lee S, Feldstein SB (2012) Mechanisms of Arctic surface air temperature change in response to the Madden-Julian Oscillation. J Climate 25(17):5777-5790

Zhang C (2013) Madden-Julian Oscillation: bridging weather and climate. Bull Am Meteorol Soc. doi:10.1175/BAMS-D-1200026.1

Zhang J, Lindsay R, Schweiger A, Steele M (2013) The impact of an intense summer cyclone on 2012 Arctic sea ice retreat. Geophys Res Lett 40(4):720-726

Zhou S, Miller AJ (2005) The interaction of the Madden-Julian Oscillation and the Arctic Oscillation. J Clim 18(1):143-159

Zhou S, Heureux ML, Weaver S, Kumar A (2012) A composite study of the MJO influence on the surface air temperature and precipitation over the continental United States. Clim Dyn 38(7-8):1459-1471 